\title{
World Congress on Osteoporosis, Osteoarthritis and Musculoskeletal Diseases (WCO-IOF-ESCEO 2019): ESCEO-IOF-WHO Collaborating Centre for Public Health Aspects of Musculoskeletal Health and Aging Symposium Abstracts (ESCEO-IOF-WHO CC)
}

(C) International Osteoporosis Foundation and National Osteoporosis Foundation 2019

\section{ESCEO-IOF-WHOCC1}

POOR ADHERENCE TO ANTI-OSTEOPOROSIS TREATMENT: DETERMINANTS, RECOMMENDATIONS FOR PRACTICE AND FOR RESEARCH

M. Hiligsmann ${ }^{1}$, B. Vrijens ${ }^{2}$, B. Abrahamsen ${ }^{3}$, on behalf of the ESCEO Working Group on adherence to anti-osteoporosis medications

${ }^{1}$ Department of Health Services Research, CAPHRI Care and Public Health Research Institute, Maastricht University, Maastricht, The Netherlands, ${ }^{2}$ AARDEX group, Liège, Belgium, ${ }^{3}$ Holbæk Hospital, Holbæk, Denmark; University of Southern Denmark, Odense, Denmark

Poor adherence to medications remains a major challenge in the treatment of osteoporosis (OP). Medication non-adherence is associated with increased risk of fractures, leading to a substantial decrease in the clinical and economic benefits of drug therapy. It is therefore extremely important to identify potential solutions to manage patient's adherence to therapy. A working group was therefore convened by IOF and ESCEO to review determinants and potential adherence-management interventions, and to make recommendations for medical practice and for further research. A systematic review and a face-to-face meeting in Geneva in January 2019 (including 21 experts) were conducted. During this IOF-ESCEO symposium, three presentations will be made to highlight the findings and recommendations of the working group, and more specifically, (1) to review the determinants of non-adherence to (OP) medications, (2) to provide recommendations for practice how to manage OP medication adherence and (3) to make recommendations for further research. These recommendations are intended for clinicians to manage adherence of their patients, and to researchers and policy makers to design, facilitate and appropriately use adherence-management interventions.

Acknowledgement: ESCEO Working Group composed of Bo Abrahamsen, Emmanuel Biver, Maria Luisa Brandi, Cyrus Cooper, Dennis Cornelissen, Bernard Cortet, Elaine Dennison, Adolfo Diez-Perez, Andrea Gasparik, Alda Grosso (patient), Peyman Hadji, Philippe Halbout, Mickaël Hiligsmann, John Kanis, Jean-Marc Kaufman, Stefania Maggi, Jean-Yves Reginster, René Rizzoli, Thierry Thomas, Sansin Tuzun, Bernard Vrijens, Nasser Al-Daghri, Olivier Bruyère, Nansa Burlet, Andrea Laslop, Mila Vlaskovska.

Publisher's note Springer Nature remains neutral with regard to jurisdictional claims in published maps and institutional affiliations. 